\title{
Algunas consideraciones metodológicas para la enseñanza-aprendizaje de las lenguas adicionales en un contexto universitario multilingüe y multicultural
}

Gregorio Pérez de Obanos Romero

Pérez de Obanos Romero, G. (2022). Algunas consideraciones metodológicas para la enseñanzaaprendizaje de las lenguas adicionales en un contexto universitario multilingüe y multicultural. Revista de Filología y Lingüística de la Universidad de Costa Rica, 48(1), e48382. doi: https://doi.org/10.15517/rfl.v48i1.48382

\section{(9) $(1) \Theta \Theta$}

Doi: https://doi.org/10.15517/rfl.v48i1.48382

URL: https://revistas.ucr.ac.cr/index.php/filyling/index 
Revista de Filología y Lingüística de la Universidad de Costa Rica

ISSN: 0377-628X

ISSN: 2215-2628

filyling@gmail.com

Universidad de Costa Rica

Costa Rica

\title{
Algunas consideraciones metodológicas para la enseñanza-aprendizaje de las lenguas adicionales en un contexto universitario multilingüe y multicultural
}

\author{
Pérez de Obanos Romero, Gregorio \\ Algunas consideraciones metodológicas para la enseñanza-aprendizaje de las lenguas adicionales en un \\ contexto universitario multilingüe y multicultural \\ Revista de Filología y Lingüística de la Universidad de Costa Rica, vol. 48, núm. 1, e48382, 2022 \\ Universidad de Costa Rica, Costa Rica \\ Disponible en: https://www.redalyc.org/articulo.oa?id=33268016008 \\ DOI: https://doi.org/10.15517/rfl.v48i1.48382
}

\section{(c) (1) $(9)$}

Esta obra está bajo una Licencia Creative Commons Atribución-NoComercial-SinDerivar 3.0 Internacional. 


\title{
Algunas consideraciones metodológicas para la enseñanza-aprendizaje de las lenguas adicionales en un contexto universitario multilingüe y multicultural
}

\author{
Methodological Considerations for Teaching and Learning of Additional Languages in a Multilingual and \\ Multicultural University Context
}

Gregorio Pérez de Obanos Romero

Universidad Federal de la Integración Latinoamericana,

Foz do Iguaçu, Paraná, Brasil

DOI: https://doi.org/10.15517/rfl.v48i1.48382

Redalyc: https://www.redalyc.org/articulo.oa?

gregorio.romero@unila.edu.br

(iD https://orcid.org/0000-0002-7743-4056

\section{Resumen:}

El artículo justifica la pertinencia de una metodología específica para la enseñanza y el aprendizaje de las lenguas adicionales, acorde con contextos educativos inmersos en procesos de internacionalización. Para ello, se describen las peculiaridades de la Universidad Federal de la Integración Latinoamericana, institución pública brasileña que aboga por una propuesta formativa de carácter interdisciplinario, intercultural y bilingüe, con el portugués y el español como lenguas vehiculares. Mediante una revisión bibliográfica y la descripción de las experiencias pedagógicas llevadas a cabo en esta universidad se trazan los cuatro componentes que conforman esta metodología: la integración de contenidos curriculares y lengua; el desarrollo de la literacidad académica; la configuración de una competencia intercultural crítica; y el incentivo de prácticas planificadas de translenguaje. No obstante, resulta fundamental analizar el potencial pedagógico de este enfoque con la puesta en marcha de proyectos de investigación sobre cada uno de estos componentes, centrados en aspectos como la planificación curricular, la formación del profesorado y la elaboración de materiales didácticos, entre los principales.

PALABRAS CLAVE: educación intercultural y bilingüe, lengua adicional, integración de lengua y contenido, literacidad académica, translenguaje.

\section{Abstract:}

This paper justifies the relevance of a specific methodology for the teaching and learning of additional languages, according to educational contexts immersed in internationalization processes. To do this, the peculiarities of the Federal University of Latin American Integration are described. This university is a Brazilian public institution with an educational proposal of an interdisciplinary, intercultural, and bilingual nature, with Portuguese and Spanish as vehicular languages. The methodology is described on four components through a bibliographic review and the description of the pedagogical experiences carried out in this university: the integration of curricular content and language; the development of academic literacy, the configuration of an intercultural competence from a critical perspective; and, finally, the incentive for planned translanguaging practices. However, it is essential to analyze the pedagogical potential of this approach through the implementation of research projects, which focus on aspects such as curricular planning, teacher training and the development of teaching materials, among the main ones.

KEYWORDS: intercultural and bilingual education, additional language, language and content integration, academic literacy, translanguaging.

\section{INTRODUCCIÓN}

El presente trabajo tiene como finalidad justificar la pertinencia de una metodología de enseñanzaaprendizaje de las lenguas adicionales ${ }^{1}$, específica para el contexto de la Universidad Federal de la Integración Latinoamericana (UNILA). En primer lugar, se señalan los pilares ideológicos y educativos que sustentan la propuesta pedagógica de esta institución pública brasileña: la formación de profesionales comprometidos con 
la integración regional mediante una educación bilingüe en español y portugués que, desde una perspectiva interdisciplinaria, propicie las prácticas interculturales.

En segundo lugar, se describe el denominado Ciclo Común de Estudios (CCE), un plan de estudios general a todas las carreras de graduación ofrecido en los primeros semestres. Entre otros cursos, que más adelante se mencionarán, se hallan los cursos de lengua adicional, cuyos objetivos y contenidos curriculares se explican con detalle en el tercer apartado.

Al tomar en consideración las particularidades de la UNILA, en la última parte del artículo, se aboga por una didáctica específica para la enseñanza de las lenguas segundas basada en cuatro dimensiones: el aprendizaje integrado de lengua y contenido, la formación para el dominio del discurso académico, el desarrollo de una conciencia crítica para el fomento de la interculturalidad y la adopción de una estrategia planificada a través de las prácticas espontáneas de translenguaje ${ }^{2}$ que se dan en este ambiente educativo multilingüe y multicultural. Con la finalidad de justificar el potencial de estas pedagogías, resulta imprescindible la ejecución de proyectos de investigación que aborden diversos aspectos de cada una, tal y como se verá más adelante.

\section{La Universidad Federal de la InTegración Latinoamericana}

La UNILA es una institución académica brasileña de carácter público creada con el propósito de fomentar la integración educativa, cultural, tecnológica y política de los países latinoamericanos mediante la enseñanza y el otorgamiento de títulos universitarios de grado y posgrado. No es casual que su sede se encuentre en la ciudad de Foz de Iguazú, en el estado del Paraná, un núcleo urbano localizado en la triple frontera entre Brasil, Argentina y Paraguay, caracterizado por su multiculturalidad y gran potencial para la integración socioeconómica y cultural de la región. Con esta vocación integracionista y solidaria nace la universidad, tal como se señala en su ley de fundación ${ }^{3}$ :

Los cursos impartidos en la UNILA serán, preferencialmente, en áreas de interés mutuo de los países de América Latina, sobre todo de los miembros del Mercosur, con énfasis en temas relacionados con la explotación los de recursos naturales y las biodiversidades transfronterizas, los estudios sociales y lingüísticos regionales, de las relaciones internacionales y las demás áreas consideradas estratégicas para el desarrollo y la integración (República Federativa de Brasil, 2010, p. 6).

De este modo, la UNILA se presenta como una novedosa propuesta en relación con universidades más tradicionales, y se concretiza con la elaboración de un proyecto pedagógico interdisciplinario mediante la oferta de contenidos curriculares comunes a todos los cursos de grado, cuyas bases se asientan en problemas e intereses compartidos por las naciones y los pueblos latinoamericanos.

\subsection{La UNILA como proyecto de universidad interdisciplinaria, intercultural y bilingüe}

En esta institución las cuestiones de orden lingüístico afectan a todas sus áreas de actuación. Por ello, la construcción de una política específica se halla condicionada por su propuesta político-pedagógica. $\mathrm{Ha}$ de considerarse, de una parte, la relación entre las lenguas y la producción y difusión del conocimiento que ocurre tanto en las prácticas de enseñanza-aprendizaje como en los proyectos de investigación; de otra parte, la construcción de una integración efectiva entre los diversos estamentos: docentes, discentes y personal administrativo. La universidad promueve la contratación de profesores cuya lengua materna (L1) es el portugués o el español y la matrícula de alumnos, tanto de brasileños como del resto de los países latinoamericanos, en una proporción de mitad de plazas para hablantes de portugués y mitad de hablantes de español o de otras lenguas del continente ${ }^{4}$. 
Por tanto, la UNILA supone la primera universidad pública brasileña de carácter bilingüe. De acuerdo con sus documentos oficiales (UNILA, 2013a, 2019a), el uso de estas lenguas constituye uno de sus principios fundacionales, lo cual afecta la esfera pedagógica, científica y administrativa. En la universidad se han de respetar e incentivar todas las formas de expresión cultural y lingüística, de este modo, se genera un espacio potencial para la vivencia intercultural, el aprendizaje de diferentes lenguas y la preparación en los estudios académicos que las identifican.

Así pues, el bilingüismo académico español-portugués, en un espacio multilingüe, la interculturalidad y la interdisciplinariedad conforman sus principios epistemológicos vertebradores. El fin es formar ciudadanos que, independientemente de su cualificación profesional, posean una comprensión global de la realidad de la región y se comprometan con el desarrollo socioeconómico equitativo entre los diferentes países que la constituyen:

[...] la interdisciplinaridad, la interculturalidad, el bilingüismo y el multilingüismo, la integración solidaria, la gestión democrática, la ética, los derechos humanos y la igualdad étnico-racial y de género, la sostenibilidad y el bienestar. Para que las temáticas latinoamericanas y caribeñas se trabajen con consistencia, en las diversas carreras, la UNILA debatirá la idea de integración entre los países de la región, basándose en la formación personal de nivel superior, científica y técnicamente competente y cualificado para el ejercicio profesional, consciente de los compromisos éticos y de la necesidad de superación de las desigualdades sociales y de la preservación del medio ambiente. Debatiendo conocimientos históricamente acumulados, trabajarán desde la perspectiva de la colaboración intelectual y la coautoría del conocimiento. En este contexto, la UNILA pretende priorizar un proceso de enseñanza y aprendizaje en que los contenidos sean fundamentales y significativos dentro de sus principios filosóficos (UNILA, 2019a, p. 34).

Con respecto a la interculturalidad, se pretende el desarrollo de vivencias académicas que permitan una mirada crítica sobre la relación de la propia cultura con las otras. Se busca la promoción del intercambio de prácticas y conocimientos que prestigien la diversidad de memorias y saberes científicos, técnicos y culturales que caracterizan a América Latina. Por tanto, es imprescindible que los estudiantes indaguen sobre los valores socioculturales que las lenguas portan, en la medida en que estas generan conocimiento y permiten el cotejo entre alteridad e identidad. De acuerdo con Quilaqueo y Torres (2013, p. 295):

[...] la interculturalidad implica una orientación ontológica, filosófica y epistemológica basada en la diversidad de las matrices culturales y en la subjetividad e intersubjetividad de las personas involucradas en relaciones que implican consensos y conflictos. Por su parte, desde el ámbito de una interculturalidad crítica, queda abierta la posibilidad de que la interacción entre los sujetos signifique el volver a mirarse para despojarse de prejuicios y estereotipos que pueden ser explícitos o implícitos.

Estas experiencias resultan inevitables en el contexto multicultural y multilingüístico de la UNILA, aún más si se considera su ubicación, ya que las fronteras geográficas suponen frecuentemente un privilegiado espacio de contacto donde se produce una negociación permanente de sentidos e identidades en los “intersticios" entre áreas políticas supuestamente homogéneas. La institución busca promocionar actividades académicas y extraacadémicas, con el objetivo de generar en los estudiantes capacidad analítica sobre las culturas, mediante la experiencia del contacto real con personas de otros países y el estudio de textos, argumentos y discursos; con esto, se construyen posibilidades de diálogo y debate cualificados.

En relación con la interdisciplinaridad, por medio de su oferta académica y su estructura administrativa ${ }^{5}$, la universidad promueve el desarrollo de un pensamiento complejo en el alumnado y la habilidad de observar el mismo fenómeno desde diferentes campos de especialización. De hecho, se persigue un enfoque multidisciplinario que permita converger áreas de conocimiento en el análisis de un determinado proceso (Pombo, 2004). Este enfoque se diferencia de la interdisciplinariedad en que este último supone simplemente yuxtaponer áreas de conocimiento, sin que dialoguen entre sí; en cambio, en el primero se produce una articulación y se establece un abordaje de acción recíproca entre las áreas. En este enfoque multidisciplinario las disciplinas establecen relaciones fuertes y confrontan perspectivas de análisis y comprensión fenomenológica. 
Las universidades brasileñas se hallan, desde esta última década, inmersas en una creciente tendencia hacia la internacionalización. La UNILA forma parte de este proceso al proponer una oferta educativa bilingüe con alumnos y profesores procedentes de los más diversos países de la región. En ese sentido, la enseñanza del español y del portugués como lenguas adicionales (LA) requiere de una planificación al servicio del desarrollo de las habilidades discursivas para la comunicación intercultural, tanto en contextos privados y sociales como académicos. Es cierto que esta propuesta no se encuentra exenta de complejidad y su puesta en práctica presenta numerosas dificultades que exigen la implicación de docentes, discentes e incluso personal administrativo, en la medida en que supone una serie de desafíos:

a) cuestionar discursos monoculturales y etnocéntricos;

b) valorizar la diversidad cultural latinoamericana mediante la promoción de actividades de interacción entre grupos de personas con diversos modos de vida y expresión;

c) capacitar para la comprensión y producción de textos en la LA.

Considerando todos estos aspectos, el desarrollo de una conciencia intercultural y la sensibilización a la diversidad sociolingüística y a la riqueza cultural de Latinoamérica constituye uno de los objetivos fundamentales del aprendizaje de las lenguas en la universidad.

Ahora bien, conviene no pecar de idealismo y se hace necesario relatar brevemente la complejidad que supone llevar a la práctica la propuesta de fortalecer el bilingüismo en la institución. La UNILA no deja de ser una institución pública que se rige por el ordenamiento jurídico y las normas de Brasil. Todo el personal técnico-administrativo y la mayoría de los alumnos y docentes son de este país; muchos no poseen un grado de dominio del español suficiente para alcanzar los desafíos mencionados. En la actualidad, la proporción existente es de un $83 \%$ de profesores brasileños y de un $17 \%$ de otras nacionalidades. Asimismo, gran parte de los alumnos no brasileños, a excepción de alumnos paraguayos oriundos de la frontera con Brasil y Argentina, acceden a la universidad sin siquiera un contacto previo con el idioma portugués. De igual modo, los estudiantes brasileños comienzan sus carreras sin conocimientos previos de español. A pesar de esta situación desfavorable, aún no se cuenta con una política lingüística institucionalizada que lidie con las consecuencias, entre las cuales se pueden enumerar las siguientes (Carvalho, 2018, pp. 12-15):

a) Las dificultades de comunicación en el ámbito administrativo debido a la falta de formación lingüística del personal administrativo.

b) La ausencia de un programa de acogida para alumnos y docentes no brasileños.

c) La diferencia de estatus entre el portugués y el español en el ámbito administrativo, académico y social de la universidad. Esto provoca, consecuentemente, que la mayoría de las prácticas, incluida la docencia y la circulación de textos en cada una de estas tres esferas, se produzca en la primera lengua en detrimento de la segunda.

d) La carencia de programas específicos de formación lingüística e intercultural dirigidos a profesores y técnicos administrativos para su actuación en este ambiente.

Tal como señala Carvalho (2018), la institución en su conjunto necesita tomar consciencia sobre la importancia de implementar acciones específicas de planificación lingüística que acaben configurando una política oficial, con el objeto de potenciar su vocación como espacio integrador de producción de conocimiento técnico-científico desde una visión latinoamericanista. No cabe duda de que, pese a las dificultades, la UNILA configura un espacio privilegiado para la aplicación de propuestas de formación intercultural, interdisciplinaria y bilingüe, tanto en los procesos de enseñanza-aprendizaje como en los de investigación que conlleven la producción y difusión de conocimientos técnico-científicos.

El aprendizaje de idiomas, sean los dos mayoritarios en la región o los minoritarios, adquiere una especial relevancia para la comprensión y estudio de los comunes procesos civilizatorios experimentados por los 
Gregorio Pérez de Obanos Romero. Algunas consideraciones metodológicas para la enseñanzaAPRENDIZA...

diversos pueblos y sociedades latinoamericanos, cuyas consecuencias han de ser problematizadas, en aras de fundamentar institucionalmente una propuesta de integración regional.

Ahora bien, ¿cómo articular desde un plano pedagógico los principios epistemológicos que estructuran la universidad?, ¿de qué modo se plasman de facto en los planes curriculares de las carreras?

\section{El CiCLo Común de Estudios}

Este núcleo de estudios representa una etapa formativa común en los planes de estudios de los veintinueve cursos de graduación que en la actualidad ofrece la universidad. Con vistas a la promoción de un pensamiento crítico en el alumnado y en atención a la especificidad de la UNILA, resulta imprescindible un enfoque interdisciplinario. Por ello, se definió la creación de un contenido curricular obligatorio conformado por tres ejes temáticos:

a) "Epistemología y Metodología"

b) "Estudio comprensivo sobre América Latina" (posteriormente denominado "Fundamentos de América Latina")

c) “Lenguas adicionales", español o portugués

Este ciclo formativo se imparte a lo largo de los tres primeros semestres y contabiliza, en su conjunto, treinta créditos. A su término, se espera la adquisición de un grado aceptable de dominio lingüístico por parte del estudiante: el portugués para hispanohablantes y el español para brasileños. Además, se espera que el alumno disponga de conocimientos y habilidades para la apropiación de cuestiones relevantes acerca del desarrollo de esta región geopolítica y la presentación de soluciones a los problemas identificados en ella (UNILA, 2013b).

Así pues, el objetivo general es la proporción de una base formativa de carácter interdisciplinario que permita al estudiantado la gestación de un pensamiento crítico; un entendimiento global del contexto histórico y de la compleja actualidad de la región latinoamericana; y el manejo en diverso grado del español y del portugués en el ámbito académico.

Además, este plan curricular consideró también otros objetivos comunes a los tres ejes, atendiendo a cada fundamento vertebrador de la universidad. Junto a la interdisciplinaridad, la interculturalidad, el bilingüismo y la comprensión crítica de la realidad latinoamericana, se pretende también el desarrollo de la autonomía por medio de procesos pedagógicos que posibiliten la autogestión del aprendizaje en el alumnado.

El primer eje que vertebra el CCE, denominado "Epistemología y Metodología", se presenta en dos cursos de cuatro créditos cada uno. Su propósito es promover la reflexión filosófica en torno al proceso de construcción del conocimiento, así como la relación entre la producción científica y académica, el desarrollo tecnológico y las cuestiones de orden ético. Tal como señala el plan del Ciclo Común de Estudios (UNILA, 2013b, p. 14): “[...] tiene por objetivo examinar el proceso de elaboración de teorías y las consecuencias éticas concernientes al modo científico de aproximarse a la realidad”. La primera asignatura, ofrecida en el segundo semestre, "Introducción al pensamiento científico", supone un contacto inicial con el pensamiento filosófico occidental para lograr una base crítica de análisis que permita a los estudiantes diferenciar el conocimiento científico, en las ciencias naturales y sociales, de otras formas de saber; desarrollar habilidades críticas y argumentativas como ejercicio del quehacer científico y considerar el conocimiento crítico como medio para la integración latinoamericana (UNILA, 2013b, p. 21). De un modo complementario, "Ética y Ciencia", ofrecida en el tercer semestre, propone discutir dilemas éticos de la actualidad en la producción científica, tecnológica y académica; así como debatir el proceso de descolonización epistémica en América Latina (UNILA, 2013b, p. 21).

Los contenidos desarrollados en el segundo eje presentan al alumno un estudio sobre Latinoamérica a través del debate y el examen crítico de materiales historiográficos, sociológicos, culturales, económicos, medioambientales, entre los principales, con la finalidad de generar conocimiento comprensivo y 
sensibilización ante la realidad compleja de esta región. Se compone de tres cursos denominados "Fundamentos de América Latina", constan de cuatro créditos los dos primeros semestres y de dos créditos el tercero. Su objetivo fundamental es "[...] el estudio de las principales cuestiones vinculadas a la integración regional a partir de diferentes visiones disciplinarias y perspectivas" (UNILA, 2013b. p. 14).

El primer curso se centra en la contextualización de las principales cuestiones históricas de la región mediante el estudio de los procesos de integración y desintegración como componentes contradictorios de la historia de Latinoamérica, así como de las consecuencias del proceso colonial y su impacto con la realidad actual. En el segundo curso, se trata de comprender la región desde sus diversas dimensiones, sean estas culturales, políticas, económicas o sociales, y propiciar con ello espacios de interlocución con las trayectorias personales, experiencias vitales y visiones del mundo del alumnado. Por último, en el tercer semestre se busca la adquisición de una visión crítica del modelo actual de desarrollo de los diferentes países de la región. Para ello, se abordan cuatro grandes temas en virtud de los cuales se puede vertebrar el análisis de dicho modelo: la ocupación del espacio urbano, el desarrollo rural, el crecimiento económico mediante grandes obras de infraestructura y el respeto a la biodiversidad.

El tercer eje del CCE estriba en la formación en español/LA o en portugués/LA. Se pretende, mediante la competencia lingüística, el fomento del conocimiento académico y de la habilidad intercultural. La finalidad es preparar alumnos capaces de reflexionar y expresarse con actitud crítica en las dos lenguas vehiculares de la institución, que logren formular ideas, articular argumentos y exponer datos conforme al método científico, de tal modo que se vean capaces de abordar temas de investigación propios de la contemporaneidad latinoamericana. Este eje se estructura en dos o tres niveles, con diferente cantidad de créditos, según lo estipulado por el plan curricular de cada carrera: "[...] en los que el aprendiz desarrolla conocimientos gramaticales, pragmático-discursivos y culturales de la lengua objeto, convirtiéndose tanto en agente social como intercultural" (UNILA, 2013b, p. 7).

En el primer semestre se espera del estudiante una actuación adecuada en situaciones cotidianas del medio social y académico. Se ha de producir la adquisición de una competencia lingüística inicial, de forma tal que se integren los componentes fonético-fonológicos, morfosintácticos, léxico-semánticos, pragmáticos y discursivos, a través de una presentación de la diversidad lingüístico-cultural latinoamericana, al introducir al alumno en el universo de expresión en la LA; así como de una valorización de las variedades orales y escritas de la lengua, sean estas diatópicas, diafásicas o diastráticas, en contraste con la L1.

En el segundo curso, considerado como intermedio, se persigue que los estudiantes acrecienten las actitudes, conocimientos y habilidades lingüísticas e interculturales hasta alcanzar más seguridad en situaciones más sofisticadas de interacción. Se trabajan textos más complejos, que exigen profundizar en el estudio de los aspectos fonético-fonológicos, morfosintácticos, léxico-semánticos, pragmáticos y discursivos para una actuación más acorde con el ámbito universitario.

En el nivel avanzado del tercer semestre se tiene por finalidad la capacitación para situaciones comunicativas que requieren el dominio de un acervo lingüístico más amplio y de mayor complejidad. Se espera del alumno que posea recursos para poder participar en interacciones con un mayor grado de fluidez y espontaneidad, con un amplio repertorio para la elaboración de prácticas discursivas inherentes a la esfera académica, tales como: organizar argumentos, formular hipótesis, etc. De este modo, demostrarán una competencia argumentativa y persuasiva adecuada a las prácticas discursivas que demanda la experiencia universitaria.

El CCE colabora en varios aspectos en la formación del egresado. Entre las principales contribuciones se encuentran aquellas que lo capacitan para:

a) la activación crítica de conocimientos de su ámbito profesional para el ejercicio de la ciudadanía;

b) la obtención de un nivel de bilingüismo suficiente para la actuación eficaz en el ámbito académico;

c) el desarrollo de una conciencia intercultural necesaria para la toma de decisiones en su área de actuación laboral; 
d) la ejecución de manera interdisciplinaria de estudios sobre temas relativos a Latinoamérica.

En la actualidad, desde inicios del 2021, el CCE está pasando por una etapa de remodelación de su plan de estudios. Su principal objetivo es estrechar la relación entre sus ejes temáticos y, a su vez, estrechar la relación entre los ejes y los cursos de grado.

\section{LA ENSEÑANZA-APRENDIZAJE DE LAS SEGUNDAS LENGUAS EN LA UNILA}

El aprendizaje de la lengua adicional (LA) proporciona una experiencia intercultural mediante prácticas discursivas centradas en el desarrollo de competencias lectoescritoras, gracias al estudio y elaboración de géneros textuales variados, especialmente de carácter académico. Asimismo, la enseñanza de la LA sucede a través de la presentación interdisciplinaria de contenidos curriculares en un contexto educativo de (semi)inmersión, que considera los beneficios de la interacción cooperativa de hablantes de diversas lenguas en un ambiente pluricultural.

En otras palabras, los procedimientos didácticos y las prácticas discentes se han de fundamentar en al menos cuatro supuestos metodológicos:
a) el aprendizaje de lengua mediante contenidos curriculares;
b) la literacidad académica;
c) la competencia critica e intercultural;
d) las prácticas de translenguaje.

\subsection{El aprendizaje de la lengua mediante contenidos curriculares}

Bajo el propósito de enseñar de un modo simultáneo contenidos curriculares y L2, se contemplan diferentes modelos de aprendizaje que, a lo largo del tiempo, han recibido diferentes nombres según los momentos y los países en lo que se ha implantado ${ }^{6}$. Conviene precisar, en primer lugar, qué propuestas no caracterizan este tipo de modelos. Según Aliaga (2008, pp. 130-131), su propósito no es reforzar los contenidos académicos ya trabajados en la L1 ni enseñar una L2 teniendo como disculpa el currículum de otras disciplinas. Su objetivo tampoco es trabajar contenidos curriculares que se precisen conocer si los discentes ya dominan en la L2 las formas lingüísticas necesarias para comprender y expresar estos contenidos. Si bien no resulta del todo sencilla la caracterización de este tipo de propuestas metodológicas, sí es posible determinar lo que tienen en común: un enfoque dual de enseñanza-aprendizaje al abordar de modo simultáneo e integrado los contenidos curriculares de un curso con los de una L2 (Maljers et al., 2010). Para ello, se requiere de un docente que, a un tiempo, sea perito en una disciplina académica determinada y en la didáctica de las lenguas o, en su defecto, de dos especialistas que trabajen en cooperación (Aliaga, 2008). Entre sus principales características se hallan las siguientes (Stryker y Leaver, 1997, pp. 7-11):

a) Las actividades didácticas se corresponden con las necesidades curriculares, lingüísticas, cognitivas y afectivas de los estudiantes, lo cual demanda una adaptación flexible de los contenidos de la disciplina.

b) La gestión de la enseñanza se establece a partir de la materia académica, los contenidos lingüísticos de la L2 afloran y se derivan de esta.

c) Los materiales de instrucción no se presentan adaptados para el aprendizaje de la L2, sino que servirían también para la instrucción de hablantes nativos.

Desde hace ya décadas se viene aplicando este enfoque en contextos socioculturales y educativos diversos, desde la enseñanza primaria hasta la universidad. Su origen, en los años sesenta del siglo pasado, se remonta a proyectos de inmersión para el aprendizaje del francés en Canadá por parte de niños cuya L1 era el inglés. 
Su éxito condujo a la adaptación, una década después, para la enseñanza del español en Estados Unidos. En la actualidad existen en este país numerosos programas en que hablantes de español e inglés estudian las materias escolares en ambas lenguas. Una situación similar sucede en el nivel universitario, donde la internacionalización impulsa la expansión de modelos de aprendizaje por contenidos, adaptados al contexto institucional y al nivel de competencia en la L2 de los estudiantes (Klee y Barnes-Karol, 2006).

A partir de los años noventa, en Europa el Aprendizaje Integrado de Contenidos y Lengua tiene por objeto la formación de ciudadanos plurilingües, de acuerdo con los propósitos de la Unión Europea. En relación con la lengua española se ha dado en una doble vertiente: en países de la Unión Europea este modelo se ha empleado para su enseñanza en países como Italia, Polonia, Portugal y Francia (Llovet, 2007); en las regiones monolingües de España sirve para el aprendizaje del inglés y en las bilingües (donde es oficial el español junto a lenguas como el vasco, el catalán o el gallego) se emplea para introducir una tercera lengua en programas de inmersión con dos lenguas vehiculares previas (Comajoan, 2010; Ruiz de Zarobe y Lasagabaster, 2010).

En Latinoamérica se practican estos modelos en todos los niveles de instrucción, desde la educación infantil hasta la universidad, donde la L2 es principalmente el inglés. Por ejemplo, McDougald (2009) y Banegas (2011) detallan el panorama en Colombia y Argentina, respectivamente. Sin embargo, resulta de especial relevancia para el tema de este artículo mencionar los programas de Educación Intercultural Bilingüe puestos en ejecución en, al menos, seis países: México, Guatemala, Ecuador, Bolivia, Perú y Paraguay. Estos poseen como característica común el empleo en sus contenidos curriculares de una lengua originaria como vehículo de instrucción. Según describe López (2009), estos programas, pese a contar con apoyo institucional, no han logrado un bilingüismo permanente en el que las lenguas minoritarias se recuperen y mantengan al tiempo que los discentes adquieren también la lengua mayoritaria. En la mayor parte de los casos, sus logros han sido más bien modestos en la medida en que se produce un bilingüismo transitorio que conduce a la asimilación lingüística y a la aculturación.

En la enseñanza integrada de contenidos y lengua resulta esencial una instrucción armónica que permita no solo la atención en el contenido de la disciplina sino también en las estructuras y formas lingüísticas necesarias para la comprensión y producción de ese contenido (Lyster, 2007). "Encontrar un equilibrio adecuado entre un enfoque en el contenido y un enfoque en las formas lingüísticas sigue siendo uno de los retos principales de la enseñanza por contenidos" (Klee, 2019, p. 495). Otro aspecto relevante estriba en la distinción entre dos competencias diferentes que los alumnos han de poseer: por un lado, las destrezas básicas indispensables para la comunicación interpersonal y, por otro lado, las competencias de orden cognitivo necesarias para su desenvolvimiento en el contexto académico (Cummins, 2008). El aprendizaje por contenidos permite el desarrollo de estas habilidades cognitivas mediante actividades didácticas que propician la adquisición de ese contenido curricular, que es complejo para el discente. En ese sentido, los constructos acuñados por Vygotsky de mediación, zona de desarrollo próximo y andamiaje, contemplados en la teoría sociocultural para la adquisición de la L2 (Lantolf, 2000; Lantolf y Thorne, 2007), casan con este modelo y fomentan la integración de lengua y contenido por medio de la socialización de las prácticas discursivas inherentes a las particularidades de cada área de conocimiento.

Resulta relevante, especialmente en el ámbito universitario, la aplicación de la enseñanza por contenidos si se fundamenta en el trabajo en torno al análisis crítico y a la comprensión y producción de variados géneros textuales (Pereira, 2016). Ello es así porque los alumnos activan procedimientos perceptuales, conceptuales y cognoscitivos (Langacker, 2009), tanto en la apropiación de los contenidos lingüísticos como en la de los contenidos curriculares. De este modo, se propicia la reflexión del alumno acerca del papel que cumple la lengua en la construcción colaborativa del conocimiento en cada disciplina. Con relación a la lengua que se da en este modelo, cabe recordar la distinción entre lengua de aprendizaje, lengua para el aprendizaje y lengua a través del aprendizaje (Coyle, Hood y Marsh, 2010). La primera es aquella que los discentes necesitan para la activación de las habilidades básicas con las cuales se accede a los contenidos por trabajar. La segunda es aquella que precisan para interactuar en un entorno donde la lengua vehicular no es la materna, es decir, aquella que 
se genera gracias a la comprensión y producción de la L2, de tal modo que cuando haya dificultades, sean capaces de activar estrategias comunicativas de compensación. La tercera es aquella que surge "[...] a medida que los nuevos conocimientos, habilidades y comprensión se van desarrollando [...]. Se basa en el principio de que el aprendizaje efectivo no puede darse a menos que se produzca una implicación activa tanto de la lengua como del pensamiento" (Álvarez-Cofiño, 2019, p. 38). De acuerdo con Álvarez-Cofiño (2019), los alumnos emplean la lengua para el fortalecimiento de sus procesos de pensamiento y la aprehensión de nuevos contenidos; por medio de su aprendizaje van progresando en la adquisición de nuevos contenidos lingüísticos $y$, con ello, en el desarrollo de su L2.

Existen distintos modelos prototípicos del aprendizaje por contenidos (Tedick y Cammarata, 2012; Klee, 2019) de acuerdo con dos dimensiones: el tiempo de exposición a la L2 y el énfasis en el contenido o en la lengua. En relación con esto, resulta pertinente mencionar a Brinton, Snow y Wesche (2003), quienes establecen, a partir de una clasificación inicial de Met (1999), una taxonomía siguiendo un continuo que va desde los modelos más centrados en el contenido a los más centrados en la lengua. Mientras que en los primeros el objetivo se centra más en la adquisición de los contenidos especificados en un plan de estudios, en los segundos la atención se centra más en aspectos léxicos y gramaticales de la L2 mediante los contenidos del curso. Entre ambos extremos, enfoque en el contenido (modelos de inmersión total o parcial) y enfoque en la lengua (uso del contenido para practicar la lengua), se hallan al menos tres modelos más en esa gradación: la inmersión estructurada (el objetivo recae en el contenido y el aprendizaje de la L2 es más bien incidental), la instrucción adjunta (se encontraría en el medio de este continuo) y, finalmente, la instrucción de lengua basada en temas (centrada principalmente en la enseñanza de la lengua). A continuación, se exponen brevemente algunas características de estos modelos intermedios.

La instrucción de lengua basada en temas ${ }^{7}$ consiste en una clase de L2 que se estructura en torno a los contenidos de un curso. El docente es perito en la didáctica de la L2, pero habitualmente no lo es en la disciplina que enseña. Según avanza el curso, se introducen nuevos temas que suministran los contenidos académicos, pero fundamentalmente son un punto de partida para la presentación y el desarrollo de nuevos contenidos lingüísticos: estructuras formales, funciones lingüísticas, combinaciones léxicas del área de conocimiento abordado, etc. Así pues, la finalidad es el aprendizaje de la L2 mediante la combinación de los procesos, elementos y dinámicas de una clase de lengua con los temas, géneros textuales y prácticas discursivas características de una determinada área académica.

En la instrucción adjunta ${ }^{8}$, los alumnos con un cierto nivel en la L2 se encuentran matriculados en un curso, pero cursan de forma simultánea un programa de apoyo con clases de $\mathrm{L} 2$. $\mathrm{Al}$ aunar clases de lengua, cuya finalidad se centra en la L2, con una materia académica, cuyo enfoque recae en el aprendizaje de su contenido, se situaría en la posición media entre los dos lados de la balanza que supone el enfoque en la lengua y el enfoque en el contenido (Klee, 2019, p. 499).

Desde una perspectiva técnico-administrativa, es sin duda el más exigente puesto que demanda de un esfuerzo de coordinación entre dos especialistas, cada uno en su área, que colaboren incluso interdisciplinariamente, de tal modo que cada uno de los dos contenidos se vean de algún modo (re)adaptados en aras de su complementación.

La inmersión estructurada ${ }^{9}$, por su parte, se fundamenta en la enseñanza de la materia de un curso en una lengua vehicular que supone una L2 para los alumnos matriculados. El docente es un especialista en el área académica, no en la didáctica de lenguas. Ahora bien, dadas las características de los discentes, se verá obligado a adaptar su gestión del aula a técnicas pedagógicas que faciliten la comprensión de los contenidos de la materia. Estas modificaciones suponen un apoyo lingüístico y un andamiaje conceptual necesario para la adquisición del contenido de una disciplina impartida en L2.

No obstante, el hecho de que estos docentes no se consideren profesores de L2 puede suponer que no pongan el suficiente interés en el aprendizaje de la lengua y que, en caso de que este ocurra, sea en su mayor parte incidental. $\mathrm{Al}$ no haber atención a las formas lingüísticas, se corre el riesgo de que la interlengua del 
aprendiz no avance hacia un nivel de competencia mayor (Lyster, 2007; Tedick y Cammarata, 2012). Para evitar esto, entre las principales técnicas de facilitación lingüístico-conceptual se encuentran las siguientes (Klee, 2019):

a) Crear un plan de clases estructurado con actividades de anticipación y repaso.

b) Proporcionar al inicio de la clase un esquema para facilitar que los alumnos puedan seguir el desarrollo de actividades.

c) Ajustar equilibradamente la cantidad de lectura que se les asigna a los alumnos como tarea.

d) Hablar con dicción y lentitud repitiendo ideas y terminología claves.

e) Ofrecer fichas de lectura para la comprensión de textos difíciles.

f) Repetir el contenido con diversas actividades.

g) Brindar auxilio de tipo lingüístico en las actividades escritas.

h) Elaborar pruebas de evaluación, de forma tal que no se desfavorezca a los alumnos que comprenden el contenido, pero muestran dificultades con la L2.

Considerados algunos principios generales y los principales modelos de instrucción, conviene una reflexión acerca de su posible aplicabilidad en la UNILA. Sin duda, el aprendizaje del español o del portugués como LA mediante contenidos curriculares supone un procedimiento metodológico fundamental para el desarrollo de una literacidad académica que permita a los discentes un desenvolvimiento satisfactorio en el ámbito universitario.

Dada la compleja realidad sociolingüística y la pluralidad de culturas y prácticas académicas que entran en contacto en la universidad, resulta posible la puesta en práctica de cada uno de los diferentes prototipos metodológicos presentados, bien los más enfocados en el contenido, bien los más centrados en la lengua.

La UNILA es un espacio académico bilingüe y de convivencia multilingüística y multicultural que brinda a aquellos alumnos cuya L1 no es el portugués una experiencia de total inmersión lingüistica en esta lengua. Del mismo modo, los alumnos brasileños se hallan en una situación de inmersión parcial, en la medida que también se ven expuestos al español como lengua vehicular en algunas disciplinas a lo largo de su carrera, o en contacto con esta lengua en espacios de convivencia social, así como en eventos académicos organizados por la institución. Esta universidad, como se ha comentado, tiene la responsabilidad de favorecer la superación de la diglosia actual entre las dos lenguas y de promover una política lingüística ${ }^{10}$ que, por un lado, garantice un efectivo bilingüismo académico y, por otro lado, visibilice las lenguas minoritarias que coexisten en ella. Con ello, se conseguirá no solamente el respeto y la valorización de las culturas y las personas que se hallan vinculadas a las lenguas, sino también un privilegiado entorno que favorezca el aprendizaje incidental de estas lenguas en sus usos académicos, sociales y privados.

En relación con la taxonomía mencionada de modelos con un enfoque dual de combinación de lengua y contenido, corresponde señalar las siguientes consideraciones. La enseñanza del español o el portugués en el Ciclo Común de Estudios supone indudablemente un espacio donde se da un uso efectivo, si bien no sistemático, de contenidos curriculares en áreas de práctica significativa de la LA. Esto ocurre en una doble vertiente: por una parte, en el empleo de contenidos de los otros ejes del CCE; por otra, en el trabajo con contenidos de los cursos o al menos de las grandes áreas de conocimiento de los que estos forman parte ${ }^{11}$. Entre las principales prácticas didácticas en la clase de lengua que persiguen este fin se encuentran las siguientes:

a) La aplicación de un análisis de necesidades de los alumnos matriculados en relación con su área de formación y el rol de las lenguas, en aras del desarrollo de procesos cognitivos complejos y necesarios en el ámbito universitario.

b) El uso de textos académicos compartidos en clase de LA y en los cursos de contenido (sea uno específico de la carrera, o uno del eje de "Fundamentos de América Latina" y/o de "Epistemología 
y Metodología"); la clase de lengua funge de apoyo lingüístico para la presentación de estructuras gramaticales y de léxico de especialidad, la clase de contenido, por su parte, sirve para la aprehensión de las ideas y conceptos clave.

c) Las prácticas discursivas de expresión escrita y oral en LA a partir de temas y contenidos curriculares pertenecientes a los cursos de los aprendices y según su nivel de dominio lingüístico: elaboración de carteles, fichas de lectura, mapas conceptuales, resúmenes, reseñas, presentaciones orales, debates, etc.

No obstante, es posible dar un paso más allá y avanzar hacia modelos que se encuentran en los estadios intermedios del continuo entre lengua y contenido. La instrucción de lengua basada en temas es perfectamente adaptable a las materias del eje español-portugués del CCE y en estos momentos se contempla esta posibilidad en la reforma que se está llevando a cabo en el plan curricular de este ciclo formativo. Para ello, se está considerando la adopción de una serie de medidas:

a) La elección de un conjunto de textos académicos, común a los tres ejes del CCE, que formen parte de su bibliografía básica.

b) El refuerzo en el área de LA, mediante el trabajo de diferentes géneros académicos que sirvan de apoyo al eje de "Fundamentos de América Latina” y al eje de "Epistemología y Metodología”, según las necesidades de cada semestre.

c) La definición de objetivos comunes a los tres ejes, tanto en contenidos como en el desarrollo de habilidades y actitudes.

d) La aplicación de evaluaciones integradas a través de las cuales los estudiantes presenten en la LA sus producciones orales y escritas.

e) La inclusión en los contenidos curriculares de los ejes temáticos de las especificidades de los cursos de grado.

En relación con los otros dos modelos del continuo, la instrucción adjunta y la instrucción estructurada, cabe afirmar su aplicabilidad al contexto de la universidad. Si bien en este momento no se están llevando a cabo, su implementación supondría sin duda una innovación en la enseñanza-aprendizaje de las LA, tanto en la planificación curricular como en las prácticas académicas docentes y discentes.

En el caso de la instrucción adjunta, clases conformadas por alumnos de ambas lenguas se beneficiarían de la colaboración de grupos de tres profesores: el especialista en el contenido del curso y los especialistas en la didáctica de cada una de las lenguas. Mediante un trabajo interdisciplinario, previo y posterior al comienzo de las clases, se daría la enseñanza integral del contenido, supeditando la presentación y el desarrollo de los contenidos y habilidades lingüísticos en la LA conforme a las necesidades académicas.

En el caso de la inmersión estructurada, antes de su puesta en práctica, se haría imprescindible el diseño - por parte de especialistas en la didáctica de la LA- de talleres de formación para los profesores que deseen adaptar a la docencia en L2 los contenidos curriculares en los que son especialistas. Este proceso de capacitación consistiría no solamente en el adiestramiento de las lenguas vehiculares en que se impartirá el curso, sino también de las técnicas pedagógicas que contemplen la sensibilización hacia las dificultades lingüísticas que enfrentarán los discentes en la aprehensión de los contenidos. La finalidad es que el profesor no pierda de vista que, entre los objetivos de su curso, se encuentra también propiciar el desarrollo de la interlengua de los alumnos, por medio de actividades de atención a la forma, léxico y estructuras gramaticales que faciliten la comprensión de las ideas y los temas clave de la malla curricular.

La UNILA, como laboratorio de experimentación en prácticas lingüísticas innovadoras, tiene ante sí el reto de diseñar y ejecutar proyectos de investigación, cuya finalidad sea la validación de la efectividad de estos modelos pedagógicos. De este modo, busca fortalecer la relevancia de una pedagogía efectivamente integradora de la lengua y el contenido curricular. 


\subsection{La literacidad académica}

La adquisición de las LA por medio de contenidos curriculares en la UNILA guarda una estrecha relación, en primer lugar, con el estudio del español y del portugués como lenguas de especialidad; en segundo lugar, con su enseñanza con fines específicos, debido al grado de complejidad y profesionalización de los contenidos abordados en cada una de las carreras; por último, con la conformación de un español y un portugués académico en el ámbito universitario, y la investigación sobre su didáctica para el estudiantado no nativo.

Gómez de Enterría (2009, pp. 19-20) define las lenguas de especialidad como: "lenguas de las ciencias, las técnicas y las profesiones [...] surgen y se desarrollan paralelamente al progreso de las diferentes ciencias y técnicas, y son empleadas para llevar a cabo la transmisión de los conocimientos especializados”. Aunque comparten estas características lingüísticas y funcionales comunes, presentan entre sí marcadas diferencias, ya sea por su pertenencia a un área de especialidad determinada: ciencias experimentales, exactas, humanas, sociales, entre otras; ya sea por su materialización en situaciones comunicativas concretas, que condicionan su nivel de empleo en la divulgación académica. El discurso académico -resulta pertinente esta precisiónno consiste únicamente en la lengua de la comunidad científica, sino también en el código escrito y oral que profesores y alumnos emplean para presentar, debatir, evaluar y aprender contenidos de orden científico. En el contexto de la educación superior, Regueiro y Sáez (2013, p. 16) precisan que el lenguaje académico es aquel que se emplea en los textos orales y escritos característicos de la universidad, realizados por sus miembros, quienes se constituyen en una comunidad discursiva con un amplio conjunto de objetivos comunes: la creación y transmisión de conocimiento, y el desarrollo de vías de intercomunicación expresados mediante diversos géneros textuales.

En este contexto, la competencia comunicativa supone la adecuada comprensión y producción de textos orales y escritos: clases magistrales, presentaciones, conferencias, debates, seminarios, carteles, reseñas, exámenes, trabajos de fin de curso, etc. (Pastor, 2014, pp. 19-20). Por ello, la enseñanza del discurso con fines académicos se concibe, de acuerdo con Vázquez (2004, p. 1130, la cursiva es del original), como:

[...] una disciplina que investiga las características de los géneros académicos -en un amplio sentido de la palabra- con el objetivo de facilitar a personas no nativas de una lengua la adquisición de destrezas que les permitan cumplir con éxito tareas propias de los ámbitos universitarios, entre otras producir textos y comprender clases magistrales. La investigación se extiende a otras áreas relacionadas: el currículum, el análisis de necesidades, los objetivos, los marcos teóricos y análisis de corpora, el enfoque metodológico (procesos y productos), los entornos de aprendizaje, la evaluación, las estrategias de comprensión y producción, la gramática del texto académico, los materiales y otros estudios, como puede ser el de la perspectiva de la lengua materna.

La mejora en las capacidades lingüísticas necesarias para el desenvolvimiento del alumnado en la universidad exige del profesorado, a su vez, una formación especializada en el dominio de los componentes de la comunicación académica y profesional, y la organización del proceso de enseñanza-aprendizaje para adaptarlo a las necesidades reales de los estudiantes (Aguirre, 2012, p. 5).

De igual modo, esta metodología requiere el fomento de la denominada literacidad académica. El término (Carlino, 2005) engloba las nociones y estrategias necesarias para la participación de los alumnos en la cultura discursiva de las disciplinas, así como en las actividades de comprensión y producción textual requeridas para aprender en la universidad. Según la autora, el concepto apunta a las prácticas de lenguaje y pensamiento propias del ámbito académico. Por su parte, Chávez y Cantú (2015) lo conciben en su definición como práctica letrada y sociocultural que los estudiantes realizan por medio de actividades y tareas propias de una institución educativa con el fin de evidenciar el uso discursivo disciplinar que les es propio, de acuerdo con su formación académica. Esta práctica se ve reflejada a través de géneros discursivos y tipos de textos académicoprofesionales. El aprendizaje de la literacidad académica implica un proceso de participación en estas prácticas socioculturales letradas que definen a una comunidad académica concreta. 
En Latinoamérica cada vez son más numerosos los programas de intercambio entre universidades; como resultado, también son más los estudiantes que asisten a clases en español o portugués, sin ser esta su L1, y que a un tiempo podrían aprender los contenidos curriculares y la lengua en la que se imparten. Resulta, sin duda, un reto que se halla determinado por una serie de condicionantes que Pastor (2014, pp. 3-4) sintetiza en al menos tres: la implicación del profesorado, la buena disposición del alumnado y el diseño de materiales didácticos adaptados que sirvan de apoyo lingüístico para facilitar la adquisición de los contenidos.

Ha de considerarse, de un lado, la cantidad y calidad de input lingǘstico a la que se ven expuestos los alumnos, ya que estas determina las posibilidades de un aprendizaje significativo de la L2; de otro, el papel que juegan los hablantes no nativos y el diverso grado de literacidad académica, en su L1 y en la L2, que poseen al ingresar en la universidad; y por último, factores de orden institucional, como la presencia de una o varias lenguas vehiculares en el aula o las diferentes posibilidades de adaptación de este modelo pedagógico a las características de una institución académica determinada, entre los principales.

Este modelo de enseñanza-aprendizaje, aún en ciernes en la región latinoamericana, puede resultar exitoso si se dan los requisitos adecuados. De acuerdo con Pastor $(2014$, p. 2), se hacen necesarios proyectos de investigación que atiendan:

[...] en especial en lo relativo al análisis de la situación y la identificación de necesidades de los estudiantes no nativos en la universidad, por un lado, y al estudio lingüístico, textual y pragmático del español académico, el perfil que deben tener los recursos y materiales didácticos o la intervención del profesorado, por otro.

En el caso específico de la UNILA, debe considerarse la diversidad lingüística, sociocultural y el bagaje educativo del estudiantado en el momento de su ingreso a la universidad. Como consecuencia de ello, se da la existencia de una amplia heterogeneidad de grados de competencia a la hora de desenvolverse en las prácticas discursivas propias del entorno académico, tanto en la L1 como en la LA. En la mayoría de las ocasiones, el alumnado accede a la educación superior con una competencia lingüística insuficiente, en español o portugués, lo cual puede afectar su rendimiento académico y, por lo tanto, la tasa de permanencia en la institución.

A fin de investigar el papel que pueden desempeñar los cursos de LA en el CCE, Ferreira (2015) realizó un sondeo entre docentes y discentes acerca de las necesidades de formación específica en literacidad académica, a partir de las prácticas lectoescritoras que se producían tanto en los cursos del propio CCE como en los específicos que forman parte del plan de estudios de algunas carreras. La autora llegó a la conclusión de que estas prácticas se encuentran estrechamente relacionadas con las actividades pedagógicas que se producen en la clase y con el manejo de los diversos géneros técnico-científicos propios de la comunidad académica.

En relación con la comprensión lectora (Ferreira, 2015, p. 40), muchos estudiantes afirman que esta habilidad es imprescindible para el seguimiento adecuado de los contenidos del curso, la realización de debates en clase y la posterior evaluación. Reconocen que al comienzo de la carrera sienten dificultad en la comprensión de bibliografía en LA. Por su parte, los docentes señalan que una parte de los alumnos no cuentan con un dominio suficiente en la comprensión de textos académicos, incluso en L1. Respecto a la expresión escrita, los estudiantes, en general, emplean su L1, ya que pueden elegir a lo largo de la carrera la lengua en la que van a redactar los textos. Aunque "la lectura en lengua adicional sería el mayor reto del proyecto en lo referente al bilingüismo [...]. Sin embargo, la escritura en registro académico supone también una dificultad a superar, según estudiantes y docentes" (Ferreira, 2015, p. 47). La investigación concluye que la literacidad académica en L1 debe trabajarse también, pues una gran parte de los aprendices no se hallan familiarizados con textos académico-científicos que abordarán en la graduación. Los estudiantes carecen no solo de conocimientos previos acerca de los géneros académicos, sino incluso de habilidades lectoescritoras propias de la educación secundaria.

Asimismo, ha de considerarse el diverso perfil lingüístico de los estudiantes matriculados en la universidad, especialmente hablantes de lenguas originarias (algunos de ellos con una incompleta alfabetización en 
español) y hablantes del criollo haitiano, alfabetizados en francés. Muchos de ellos se enfrentan a la dificultad de leer y escribir en las dos lenguas vehiculares de la universidad. Todos estos aspectos apuntan a la necesidad de valorar esta diversidad multilingüística en el proceso de enseñanza-aprendizaje de los cursos de graduación, con el fin de promover una mayor inclusión de estos grupos de alumnos en las actividades académicas.

Todas estas particularidades mencionadas permiten la reconsideración del papel que pueden desempeñar los cursos de lengua del CCE en aras del desarrollo de las habilidades de lectoescritura, para lograr un rendimiento académico eficaz de los estudiantes en las carreras. La cercanía tipológica entre el portugués y el español propicia, ya desde el inicio de sus estudios, que el alumnado, tanto nativo como no nativo, pueda cursar materias en las que se una el aprendizaje de contenidos lingüísticos con la comprensión y producción de textos y discursos. La enseñanza de las LA suple la necesidad de que el alumnado pueda interactuar en las lenguas de la institución, y la de que negocien sentidos sobre sí mismos y sobre el otro en el ámbito privado, en el público y en el académico.

Así pues, en consonancia con las demandas propias de la internacionalización de las universidades y de la formación técnico-científica de cada carrera y/o área de conocimiento, las cuestiones relacionadas con la literacidad académica se convierten en uno de los principales objetivos de la oferta de los cursos de lengua adicional del CCE. Por ello, el nuevo plan de estudios del Ciclo Común que, como se ha mencionado, se encuentra en fase de desarrollo, atiende esta necesidad incluyendo en el syllabus de los cursos de LA este aspecto formativo. En los dos primeros semestres todos los alumnos completarán ocho créditos, divididos en dos cursos denominados "Prácticas discursivas e interculturales en español o portugués” I y II. El objetivo del primero es el desarrollo de estrategias, habilidades y conocimientos lingüísticos y socio-discursivos para la comprensión y producción de variados géneros textuales, en situaciones comunicativas del ámbito cotidiano y académico; en el segundo curso, estas prácticas discursivas se amplían a contextos comunicativos propios de la esfera social y académica. Se observa también una gradación en la práctica de la comprensión y producción entre los dos cursos. En el primer semestre se propicia la lectura de carteles, infografías, fichas, resúmenes, capítulos de libros, artículos periodísticos, académicos y de divulgación científica, junto a la escucha de debates, entrevistas y clases expositivas; mientras que en el segundo los estudiantes abordan, además, la comprensión escrita de otros tipos de textos, como proyectos de investigación, fragmentos de trabajos de conclusión de grado, ensayos, crónicas y artículos de opinión y divulgación científica, así como la comprensión oral de debates, entrevistas y conferencias. En relación con la producción, en el primer curso se incita a la redacción de diálogos, biografías, cartas de presentación, noticias, correos electrónicos y resúmenes de artículos académicos; mientras que en el segundo se trabaja la expresión escrita y oral de relatos de experiencia, apuntes de clase, diálogos más complejos, fichas, comentarios críticos, reseñas y exposiciones orales y debates.

En el tercer semestre, la oferta de LA del CCE se amplía a una propuesta de hasta trece cursos, de dos créditos; cada alumno deberá escoger uno y su prerrequisito es la conclusión de los dos semestres anteriores. Dentro de esta oferta se proponen dos cursos que permiten al estudiante la posibilidad de profundizar su formación en este ámbito. El primero, "Español o Portugués para fines específicos: comprensión y producción oral y escrita", tiene por objetivo el desarrollo de la competencia comunicativa en la LA, en español o en portugués, para el desenvolvimiento en las actividades relativas a la futura profesión del estudiante. Se busca la consolidación de las habilidades estratégicas, lingüísticas y socio-discursivas, imprescindibles al área de conocimiento del alumno, y el dominio de la lengua de especialización de su ámbito profesional, así como la adquisición de la terminología propia de su futura profesión. La segunda oferta tiene por nombre "Lectura, producción e interacción oral en géneros académicos del español y del portugués". La finalidad es que los estudiantes consoliden sus prácticas de lectoescritura y acaben dominando la producción de los principales textos del ámbito académico. A diferencia de los cursos mencionados hasta el momento, en este último la oferta va dirigida a todo tipo de alumnos, independientemente de su L1, que conformarán grupos mixtos. 
Asimismo, los cursos de grado que lo deseen tendrán la posibilidad de incluir en su plan de estudios la oferta de un curso optativo, el cual tendrá como prerrequisito la conclusión del CCE. Con dos créditos de carga horaria, "Preparación para el Trabajo Final de Carrera y artículos científicos en español o portugués" tiene por finalidad la adquisición de competencias en redacción y exposición oral académica para la producción y defensa pública del Trabajo Final, así como la familiarización con los modelos discursivos de los artículos científicos y con las estrategias de su divulgación.

Tal como se ha mencionado en la sección anterior, resulta también imprescindible que el cuerpo docente del área de Letras-Lingüística de la UNILA realice proyectos sobre el portugués y el español académico considerando al menos las siguientes tres líneas de investigación: la textual, la didáctica y la sociocultural. En la primera hay que observar los diversos géneros académicos y la tipología textual, a partir de la identificación de las diversas comunidades discursivas de la universidad y del análisis del corpus producido por docentes y discentes, considerando una perspectiva del contraste español-portugués. En la segunda se deben planificar cursos, crear materiales, recursos y guías didácticos para evaluar la efectividad de diferentes modelos pedagógicos para la enseñanza-aprendizaje del español y del portugués académico, tanto en L1 como en L2, así como considerar la integración didáctica de la literacidad académica en las dos lenguas vehiculares con grupos mixtos de alumnos, a partir del trabajo de pares de docentes especialistas en cada una de ellas. En tercer lugar, es necesario estudiar las diferentes tradiciones académicas que entran en contacto y analizar de un modo empírico los choques culturales, por medio de un enfoque de contrataste pragmático intercultural.

\subsection{La competencia crítica e intercultural}

El incremento de las habilidades discursivas orales y escritas en el ámbito académico de la UNILA, además de la vivencia cotidiana que se genera en los diferentes espacios de la universidad, ofrece a los estudiantes oportunidades para intervenir en multitud de situaciones de mediación intercultural. De acuerdo con García y Menken (2010, p. 252), en los espacios donde coexisten grupos de diferentes procedencias, las interacciones multilingües demandan el desarrollo de una consciencia de la cultura propia y de la cultura del otro a fin de que se puedan llevar a cabo prácticas pedagógicas adaptadas a sus necesidades.

La enseñanza-aprendizaje de las LA es indudablemente un lugar privilegiado para la discusión acerca de cuestiones de orden intercultural, en la que no se persigue únicamente el incremento de la competencia lingüística, sino un proceso vivencial a partir de intercambios dialógicos y dialécticos, donde se da relevancia a cuestiones de etnia, clase, identidad, lengua, edad o género, entre otras (Jackson, 2014). Tal como señalan Rodrigues y de Faria (2019, p. 122): "el desarrollo de una competencia intercultural ayudaría a los aprendices a no comportarse como modelos estereotipados de un determinado hablante nativo, sino que fortalecería las identidades y se orientaría hacia una preocupación política y social”. El aprendizaje de la L2 se concibe como un proceso de interacción que se adiciona al repertorio lingüístico ya existente en los aprendices, no como algo ajeno. De este modo, su didáctica debe proporcionar textos relevantes para que estos puedan:

[...] comprender mejor su propia realidad y a aprender a actuar con desenvoltura, flexibilidad y autonomía en el mundo en que viven y, así, ser individuos cada vez más activos en la sociedad contemporánea, caracterizada por la diversidad y la complejidad cultural (Schlatter y Garcez, 2009, p. 127).

Resulta pertinente, empero, detenerse en el concepto de competencia intercultural desde la perspectiva de la didáctica de las LA. En general, se distinguen dos clases de definiciones, según se centren en la eficacia de la comunicación o en la transformación personal (Jiménez-Ramírez, 2019, p. 245). Dentro de la primera se encuentra la de Martín Peris (2008) ${ }^{12}$, que concibe la competencia intercultural como: "La habilidad del aprendiz de una segunda lengua o lengua extranjera para desenvolverse adecuada y satisfactoriamente en las situaciones de comunicación intercultural que se producen con frecuencia en la sociedad actual, caracterizada por la pluriculturalidad". En cambio, otros autores (Hinkel, 1999; Liddicoat, 2009) inciden más en la idea de 
proceso transformador de la identidad del aprendiz para definir la competencia intercultural. En cualquier caso, desde ambas perspectivas se le concibe como un negociador de significados, pues expresar sentidos en una LA exige mediación y el establecimiento de puentes de entendimiento entre la propia cultura y las otras (Oliveras, 2000; Roberts y Byram, 2001). El hablante intercultural posee una macrocompetencia que le permite mediar entre culturas, lenguas y visiones del mundo, y establecer vínculos entre ellas (García y Kharnásova, 2012).

Ahora bien, ha de tomarse en cuenta que la enseñanza de las LA en la UNILA concibe el desarrollo de las competencias interculturales como un proceso comunicativo dinámico, versátil y crítico de la identidad y, por ende, de la cultura propia y ajena. Esta visión de la interculturalidad bebe de diversas disciplinas y corrientes teóricas, principalmente de la interculturalidad crítica y los Estudios Críticos del Discurso.

Desde finales de los años 90, surge el enfoque crítico para la educación intercultural a partir de supuestos de una pedagogía que tiene por finalidad formar ciudadanos críticos (Freire, 2000; Canagarajah, 2005). Se trata de facultar a los aprendices para que puedan posicionarse de un modo reflexivo acerca de cuestiones políticas y sociales. Con ello, serán capaces de discernir, a partir de la dimensión ideológica de las relaciones sociales y culturales, los aspectos opresores de la sociedad (Pennycook, 2004).

De acuerdo con Guilherme (2002), la educación intercultural desde una perspectiva crítica debe incentivar una serie de operaciones cognitivas con el fin de cuestionar, comparar, analizar, negociar y actuar, con relación a las propias creencias, valores y actitudes culturales, y con las de los otros. La competencia intercultural crítica (Huber y Reynolds, 2014) se define como un conjunto de actitudes, saberes y habilidades empleados por medio de acciones cuyo fin es la comprensión y el respeto a las personas percibidas como diferentes. Supone un proceso en el que los sujetos implicados en la interacción acaban por comprenderse mejor a sí mismos y al otro. El enfoque crítico implica la capacidad de cuestionar y reaprender diferentes formas de saberes y conocimientos, local y globalmente; y la de analizar su construcción a partir de los significados producidos en las relaciones culturales (Pennycook, 2004). Por tanto, "el sujeto intercultural crítico va a ser capaz de negociar sus propias representaciones sociales y políticas con las de los otros, comprendiendo que sus propias representaciones deben considerarse históricamente y se encuentran socialmente situadas" (Rodrigues y de Faria, 2019, p. 128).

Asimismo, existe todo un conjunto de corrientes educativas que se asemejan por su propósito de generar en los aprendices una conciencia crítica. Estas se han venido aplicando desde diferentes perspectivas a la enseñanza-aprendizaje de las L2 y comparten el interés común por incentivar una visión crítica de concebir las relaciones sociales, en general, y por (re)significar el proceso de adquisición de la lengua, que excede lo meramente utilitarista y adquiere una dimensión sociocultural, política y contrahegemónica. Como se ha mencionado, esta corriente se ha aplicado a las LA desde diferentes propuestas pedagógicas. Entre las principales se hallan el Pensamiento Crítico (Paul y Elder, 2003; Boisvert, 2004), los Estudios Críticos del Discurso (Fairclough, 1989 y 2008; Van Dijk, 2008) y la Pedagogía Crítica (Freire, 2000; McLaren, 2000).

La primera propuesta aborda cuestiones de la psicología cognitiva relacionadas con un modelo por competencias (conocimientos, habilidades y actitudes) que permita al alumno el desarrollo de una capacidad analítica para fundamentar sus opiniones y poner en tela de juicio lo que se dice y hace, con el fin de convertirse, por tanto, en un transformador de la realidad (Naessens, 2015). Los estudios del Análisis del Discurso, en cambio, problematizan el modo en que se reflejan en el texto construcciones ideológicas y las conexiones relacionadas con el discurso, la sociedad y el poder; mientras que la Pedagogía Crítica incide en cuestiones de transformación individual y social por medio del fomento a la autonomía del aprendiz. Para López y Martín Peris (2011, p. 509, la cursiva es del original), la competencia crítica conlleva:

[...] reconocer los diferentes "sentidos" -en plural- de los textos, a partir de los rasgos lingüísticos que posibilitan esos sentidos, pero también de los rasgos contextuales específicos: actividad social a la que sirve el texto, punto de vista de quien lo ha producido y de quien lo recibe e interpreta, grado de fiabilidad de la información, etc. Se fomenta así la participación en las prácticas sociales en las que el texto cobra sentido. Un enfoque crítico de la lectura, pues, frente a la denominada 
Gregorio Pérez de Obanos Romero. Algunas consideraciones metodológicas para la enseñanzaAPRENDIZA...

lectura acrítica, implica construir el contenido de un texto, situándolo en su contexto sociocultural de partida pero también reflexionando sobre los efectos que causa en uno mismo como lector y como individuo.

Gracias a su capacidad, el lector crítico toma conciencia de la naturaleza ideológica del texto al conseguir explicitar los prejuicios, estereotipos y sus diversas interpretaciones; descubre qué información se muestra expresamente y cuál permanece oculta; problematiza su contenido con preguntas cuyas respuestas no se explicitan en el texto; pone de manifiesto el posicionamiento del autor; y en último caso, plantea la posibilidad de una alternativa al discurso hegemónico (Atienza, 2016).

La oferta de cursos de lengua en el CCE persigue, además de las cuestiones relacionadas con la literacidad académica mencionadas en la sección anterior, la finalidad de propiciar el desenvolvimiento de una competencia crítica en los estudiantes y dotarles de la habilidad adecuada para la observación, análisis, evaluación e incorporación de las prácticas sociales de las diversas culturas que entran en contacto, y no raramente en choque, en la comunidad universitaria. El objetivo último es la mejora de su facultad mediadora y de respeto a las distintas visiones del mundo, para la formación de egresados comprometidos con la conciencia de una integración regional latinoamericana. De este modo lo expresan Pérez de Obanos y Ulloa (2019, p. 266):

Aprender un idioma debe servir para que el aprendiz entienda, de manera crítica, la cultura del país o de los países que lo hablan, con todas sus contradicciones y tensiones sociales e ideológicas. En el caso del español enseñado en Brasil, especialmente en el ámbito universitario, la enseñanza de la lengua adicional debe servir para aprender a leer el mundo latinoamericano de acuerdo a esta base teórica [...].

No cabe duda de la ambición del cuerpo docente del área de Letras-Lingüística por profundizar en esta propuesta didáctica, como queda reflejado en los syllabus del plan curricular para el nuevo CCE. En los dos cursos iniciales, "Prácticas discursivas e interculturales en español o portugués" I y II, se contempla en el primer semestre el objetivo de que los alumnos comiencen a adquirir habilidades interculturales mediante prácticas de enseñanza-aprendizaje que involucren elementos socioculturales y conformen la realidad histórica y contemporánea latinoamericana. En el segundo semestre, se busca el desarrollo de una conciencia crítica sobre esta diversidad sociolingüística y cultural.

En el tercer semestre, se le presenta al alumnado del CCE una oferta de cuatro cursos que guardan relación con estas cuestiones. En ninguno de ellos se escinde la propuesta de acuerdo con la lengua, español o portugués, sino que se ofrece tanto a alumnos brasileños como hispanohablantes, o de otros orígenes lingüísticos, a fin de formar grupos mixtos. Ello tiene por finalidad estimular prácticas y vivencias de translenguaje, aspecto que se detallará en la próxima sección. Dos de ellos abordan temas culturales del ámbito latinoamericano y los otros dos, aspectos de la interculturalidad y del análisis del discurso. Mientras que en "Diversidad del portugués y del español: Lengua y Cultura" se tiene por objeto que el alumno acceda a la compleja realidad de la región en cuestiones sociales, económicas, políticas, medioambientales o tecnocientíficas; en "Arte y Cultura latinoamericana en lengua adicional”, se propone el reconocimiento de las expresiones artístico-culturales a lo largo de su historia: música, literatura, artes visuales y audiovisuales, etc. Por su parte, en "Lenguaje y Poder en español/portugués lengua adicional" se busca la consolidación de las habilidades de análisis crítico de los textos que circulan en la esfera mediática, académica, artística o de las redes sociales, así como su intencionalidad discursiva. Finalmente, el curso "Comunicación Intercultural" se propone la consolidación en las habilidades de mediación lingüística e intercultural, por medio de una comprensión crítica de las relaciones lengua-cultura en el contexto fronterizo donde se halla la universidad, también mediante una aproximación a los comportamientos socioculturales y sus consecuencias en la interacción comunicativa.

Desde hace algunos años, se vienen estableciendo en la UNILA criterios para una metodología que potencie el fomento de las competencias interculturales desde una perspectiva crítica. Esta labor se ve reflejada en la publicación de materiales didácticos elaborados tanto para la enseñanza del portugués (Amato, 2019) 
como del español (Ulloa y Pérez de Obanos, 2019). No obstante, esta renovación curricular demanda, al igual que el aprendizaje integrado de lengua-contenidos y de la literacidad académica, de proyectos de investigación que contemple desde diversas perspectivas la competencia intercultural. Muy brevemente se perfilan, siguiendo algunos postulados de Jiménez-Ramírez (2019), los ejes que en el ámbito de esta universidad pueden resultar prometedores:

a) La identidad, las relaciones de poder y los discursos hegemónicos. Si cuestionarse la identidad y la propia cultura forma parte del proceso de aprender una L2, resulta pertinente analizar cómo esto incide en la articulación de planes de estudio y programa de enseñanza, y en la creación de actividades didácticas.

b) La elaboración de inventarios contrastivos de prácticas socioculturales, considerando tanto el plano lingüístico como el paralingüístico pertenecientes a las diversas comunidades étnico-culturales que conviven en la universidad.

c) La planificación curricular, pues resulta necesario comparar la eficacia de modelos que resuelvan de qué modo integrar la competencia intercultural desde una mirada crítica en los planes de estudio ya existentes o en los que estén por surgir.

d) El desarrollo de modelos metodológicos, específicos al contexto de la UNILA para el fomento de la competencia intercultural. Estos modelos deben estar basados en el diseño de actividades que, por un lado, contengan cuatro fases: presentación, desplazamiento, extrañamiento y evaluación; y por otro lado, motiven a los estudiantes al cuestionamiento de la propia cultura y al descubrimiento de la ajena.

\subsection{Las prácticas de translenguaje}

El término translenguaje hace referencia a las prácticas discursivas espontáneas y, en un contexto educativo, a la planificación pedagógica que propicia un uso deliberado de más de una lengua. García y Kano (2014, p. 261) definen este fenómeno, característico de espacios multilingües y hablantes potencialmente plurilingües, como:

[...] el proceso mediante el cual estudiantes y profesores se comprometen con prácticas discursivas complejas que incluyen todas las lenguas de los estudiantes para el desarrollo en la práctica de una nueva legua, el sostenimiento de las anteriores, la transmisión de conocimiento significativo y la manifestación de nuevas realidades sociopolíticas mediante el cuestionamiento de las desigualdades lingüísticas.

En el ámbito educativo esta alternancia de idiomas no supone un mero cambio de código ${ }^{13}$ o el empleo de la traducción pedagógica, sino las diversas formas multimodales en que los alumnos comprenden y producen el lenguaje en clase (Creese y Blackledge, 2015). En este sentido, "implica la construcción y uso de prácticas discursivas interrelacionadas originales y complejas que conforman el repertorio completo de idiomas de los hablantes" (Di Virgilio, 2020, p. 17). Poniendo en cuestión la tradición monolingüe, el translenguaje considera que los idiomas no son unidades separadas; los alumnos van adquiriendo nuevos conocimientos; ampliando su repertorio lingüístico; construyendo un discurso original, complejo, de códigos interrelacionados, que constituyen la expresión lingüística e identitaria de cada hablante (García, 2009). En este sentido, el translenguaje no solo posee potencialidad didáctica para la ampliación del repertorio lingüístico, sino que su expresión refleja un gesto crítico en aras del desarrollo de la conciencia social. Tal y como afirman García y Wei (2015, p. 67), "el translenguaje, como un proceso socioeducativo, permite a los estudiantes construir y modificar constantemente sus identidades socioculturales y sus valores, mientras responden a sus condiciones históricas y presentes de manera crítica y creativa”. Así pues, este fenómeno consiste, más que en el uso de las lenguas, en las manifestaciones de los hablantes bilingües y en las estrategias que utilizan para construir significados y dar voz a su multilingüismo y multiculturalidad (Hidalgo, 2018). 
Por lo comentado hasta el momento, se puede afirmar, de acuerdo con Pino, Trujillo y González (2019), que esta práctica constituye un nuevo modo de concebir el plurilingüismo, dejando de centrar la atención en las lenguas para hacerlo en los hablantes con sus discursos y su manera de dar sentido al mundo que los rodea. Todo ello repercute en las dinámicas de aprendizaje que se dan en el aula, lo cual hace de este fenómeno un término polisémico cuyas acepciones pueden observarse en tres dimensiones: la cognitiva, la discursiva y la sociopolítica. Estos tres autores, Pino, Trujillo y González (2019, p. 291) asocian las prácticas de translenguaje a:

a) la creatividad, puesto que supone la expansión del repertorio lingüístico de cada hablante;

b) la negociación de la propia identidad mediante la integración de sus recursos lingüísticos;

c) el pensamiento crítico, ya que fomenta la concienciación social al contravenir las convenciones lingüísticas y sociales;

d) un bilingüismo flexible y dinámico, que incentiva prácticas pedagógicas centradas en el cambio deliberado de los idiomas, tanto para la comprensión como para la expresión;

e) la planificación curricular que dé cabida a la riqueza lingüística de alumnos y docentes, a conceptos socioculturales e identitarios y a la alternancia de lenguas entendida más allá de la mera traducción pedagógica, del cambio de código o de la diglosia.

El trasnlenguaje, planificado como estrategia pedagógica, alberga un gran potencial, ya que resulta beneficioso en lo referente a factores cognitivos y afectivos que intervienen en el proceso de apropiación de las L2 (Di Virgilio, 2020). Desde la perspectiva de la teoría sociocultural y de los enfoques de enseñanza basados en ella, esta práctica supone un andamiaje que permite la mejora de sus habilidades cognitivas. En el aprendizaje mediante tareas lingüisticas, el uso de la L1 resulta un recurso facilitador para la resolución de problemas y la compleción de las tareas finales, para la mediación y la autorregulación del pensamiento (Fallas Escobar y Dillard-Paltrineri, 2015; Wu, 2018). Asimismo, en el aprendizaje integrado de lengua y contenido los docentes pueden alternar idiomas para facilitar la disminución del esfuerzo cognitivo de los aprendices e incentivar a que estos recurran a todo su repertorio lingüístico, con el fin de aminorar las exigencias de comprensión y expresión del contenido curricular y del lenguaje académico (Nikula y Moore, 2016; Wu, 2018). Además, de acuerdo con Di Virgilio (2020, p. 22): "el translenguaje puede funcionar como un soporte que los profesores usan para ayudar a los estudiantes a responder a las demandas cognitivas impuestas por las tareas o el contenido". Asimismo, el empleo estratégico de la L1 resulta productivo para la activación de conocimientos previos en los alumnos y su relación con la L2, y para su participación en actividades metalingüísticas.

Las prácticas planificadas de translenguaje también favorecen la creación de un ambiente emocional para la apropiación de las lenguas: "esta pedagogía conduce a un escenario más relajado que permite a los estudiantes ser más activos en clase dado que disminuye la ansiedad y fomenta la autorregulación” (Di Virgilio, 2020, p. 23).

En la UNILA, los planes de estudio de las diferentes carreras bilingües y la remodelación curricular en la nueva propuesta para el CCE, con una amplia oferta en el tercer semestre de cursos de LA para grupos mixtos de alumnos con diferentes repertorios lingüísticos, suponen un decidido avance para el incentivo a la práctica estratégica que favorezca el aprendizaje efectivo y significativo, y el uso simultáneo de la L1 y la LA a través del adiestramiento de todas las habilidades lingüísticas, incluida la mediación.

Esta universidad, caracterizada por la gran diversidad lingüístico-cultural de su profesorado y alumnado, es un ámbito académico donde las prácticas tanto espontáneas como planificadas de translenguaje ocurren de manera inevitable, incluso se podría afirmar que es un hecho consustancial a la propuesta pedagógica, lingüística e ideológica de la institución. Esto es así por varios motivos. El translenguaje incentiva el equilibrio de las relaciones de poder entre el español, el portugués y las otras lenguas de la universidad; fomenta un 
ambiente de aprendizaje y convivencia inclusivo que valora las identidades de alumnos y profesores; en definitiva, una pedagogía crítica centrada en el plurilingüismo y la multiculturalidad.

Ahora bien, tal y como se ha comentado también en las otras secciones, se hace necesaria la implementación de proyectos de investigación que dé cuenta de su valor pedagógico en el entorno educativo: el rol que desempeñan profesores y estudiantes en esta pedagogía y las prácticas de clase que se crean, así como sus aplicaciones tanto en el aula de LA como en los cursos específicos de las carreras.

\section{Conclusiones}

La formación en LA mediante la inclusión del CCE a todas las carreras de la UNILA proporciona a los alumnos la práctica significativa de discursos orales y escritos, a través de la manipulación de géneros textuales, áreas de conocimiento y temas de debate propios del ámbito académico, en una institución educativa bilingüe español-portugués que se basa en el fomento de la interdisciplinaridad y la conciencia intercultural crítica. En este contexto, el enfoque en la didáctica de las lenguas se fundamenta en cuatro ejes: el aprendizaje integrado de los contenidos curriculares y la lengua adicional, el desarrollo de las habilidades cognitivas y lingüísticas para el manejo eficaz del discurso académico, la formación de una actitud crítica ante la realidad latinoamericana y la implementación de prácticas planificadas de translenguaje.

Ahora bien, a fin de conocer con precisión el potencial pedagógico de este enfoque, es necesario poner en marcha programas de investigación específicos para cada uno de estos ejes, que de modo general se centren en aspectos como la planificación curricular, la formación del profesorado y la elaboración de materiales y recursos didácticos, entre los principales.

Retomando las palabras de Borges y Darling (2020, p. 28), la finalidad última es que el Ciclo Común de Estudios en su conjunto "pueda ser una de esas micro-utopías para concebir una institución educativa coherente con una propuesta epistemológica-política propia, comprometida con la integración [latinoamericana]".

\section{Bibliografía}

Aguirre, B. (2012). Aprendizaje y enseñanza del español con fines especificos. Madrid: SGEL.

Aliaga, R. (2008). Aprendizaje integrado de contenidos y lengua (AICLE). Revista Electrónica d'Investigació $i$ Innovació Educativa i Socioeducativa, 1(0), 129-138.

Álvarez-Cofiño, A. (2019). El enfoque metodológico CLIL (Content and Language Integrated Learning) en la Enseñanza Primaria: Estudio Comparativo de su Implementación en un Centro Bilingüe y en un Centro con Sección Bilingüe. Nebrija, 13(7), 32-54.

Amato, L. (2019). Interculturalidade crítica e português como língua adicional na universidade. En I. Coelho (Ed.), Competências no ensino-aprendizagem de linguas:pressupostos, práticas ereflexóes (pp. 141-160). Campinas, Brasil: Pontes.

Atienza, E. (2016). El desarrollo del pensamiento crítico en ELE y su evaluación. En J. de Santiago Guervós, H. Bongaerts, J. J. Sánchez Iglesias y M. Seseña Gómez (Eds), Actas del XXI Congreso de la ASELE (pp. 122-132). Salamanca: Sadmo.

Banegas, D. (2011). Content and Language Integrated Learning in Argentina 2008-2011. Latin American Journal of Content and Language Integrated Learning, 4(2), 33-50.

Boisvert, J. (2004). La formación del pensamiento crítico. Teoría y práctica. México: Fondo de Cultura Económica.

Borges, F. y Darling, V. (2020). O desafio de criar uma identidade a partir da universidade: O Ciclo Comum de Estudos da UNILA. En M. Correia, S. Rodrigues, I. Prolo y R. C Vieira (Eds.), Narrando experiências formativas que valorizam pessoas, culturas e projetos no ambiente universitário. O caso da UNILA (pp. 21-43). 
Gregorio Pérez de Obanos Romero. Algunas consideraciones metodológicas para la enseñanzaAPRENDIZA...

Recuperado de https://portal.unila.edu.br/editora/livros/narrando-experiencias-formativas-que-valorizam-pes soas-culturas-e-projetos-no-ambiente-universitario

Brinton, D. M., Snow M. A. y Wesche M. (2003). Content-Based Second Language Instruction. Michigan, EE. UU.: University of Michigan Press.

Canagarajah, S. (2005). Critical pedagogy in L2 learning and teaching. En E. Hinkel (Eds.), Handbook of research in second language teaching and learning (pp. 931-949). New Jersey, EE. UU.: Erlbaum.

Carlino, P. (2005). Escribir, leer, y aprender en la universidad. Una introducción a la alfabetización académica. Buenos Aires: Fondo de Cultura Económica.

Carvalho, S. (2018). Políticas linguísticas e integração latino-americana: desafios de uma proposta bilíngue para o ensino superior. Sures, 11, 1-29.

Chávez, G. y Cantú, L. (2015). La literacidad académica de los estudiantes universitarios. Ciencia UANL, 18(71). Recuperado de http://cienciauanl.uanl.mx/?p=3050

Comajoan, L. (2010). La enseñanza de lenguas en España y el reto del multilingüismo europeo. Hispania, 93(1), 123-129.

Coyle, D., Hood, P. y Marsh, D. (2010). Content and Language Integrated Learning. Cambridge: Cambridge University Press.

Creese, A. y Blackledge, A. (2015). Translanguaging and Identity in Educational Settings. Annual Review of Applied Linguistics, 35, 20-35.

Cummins, J. (2008). BICS and CALP: Empirical and Theoretical Status of the Distinction. En B. Street y N. Hornberger (Eds.), Encyclopedia of Language and Education (Vol. 2, pp. 71-83). Nueva York: Springer.

Di Virgilio, A. (2020). Translenguaje: derribando barreras en el aula de lenguas extranjeras. Revista digital de Politicas Lingüisticas, 13, 6-33.

Fairclough, N. (1989). Language and power. London: Longman.

Fairclough, N. (2008). El análisis crítico del discurso y la mercantilización del discurso público: las universidades. Discurso y Sociedad, 2(1), 170-185.

Fallas Escobar, C. y Dillard-Paltrineri, E. (2015). Professors' and Students' Conflicting Beliefs about Translanguaging in the EFL Classroom: Dismantling the Monolingual Bias. Revista de Lenguas Modernas, 23, 301-328.

Ferreira, L. (2015). Práticas de leitura e escrita ao longo dos cursos de graduação na UNILA: subsídios para o ensino de línguas adicionais. Intercâmbio, 30, 29-50.

Freire, P. (2000). Pedagogia da autonomia. São Paulo: Paz e Terra.

García, B. y Kharnásova, G. (2012). La interculturalidad como macrocompetencia en la enseñanza de lenguas extranjeras: revisión bibliográfica y conceptual. Porta Linguarum, 18, 97-114.

García, O. (2009). Education, Multilingualism and Translanguaging in the 21st century. En T. Skutnabb-Kangas, R. Philipson, A. K. Mohanty y M. Panda (Eds.), Social Justice Through Multilingual Education (pp. 140-158). Bristol, Inglaterra: Multilingual Matters.

García, O. y Kano, N. (2014). Translanguaging as Process and Pedagogy: Developing the English Writing of Japanese Students in the US. En J. Conteh y G. Meier (Eds.), The Multilingual Turn in Languages Education: Opportunities and Challenges (pp. 258-277). Bristol, Inglaterra: Multilingual Matters.

García, O. y Menken, K. (2010). Stirring the onion: educators and the dynamics of language education policies. En O. Garcia y K. Menken (Eds.), Negotiating language policies in schools: educators as policy makers (pp. 249-261). New York: Routledge.

García, O. y Wei, L. (2015). Translanguaging and Education. En Translanguaging: Language, Bilingualism and Education (pp. 63-77). London: Palgrave Pivot.

Gómez de Enterría, J. (2009). El español lengua de especialidad: enseñanza y aprendizaje. Madrid: Arco.

Guilherme, M. (2002). Critical Citizens for an Intercultural World: Foreign Language Education as Cultural Politics. Clevedon, Inglaterra: Multilingual Matters. 
Hidalgo, A. V. (2018). Implicaciones lingüísticas, sociales y pedagógicas del translenguaje frente a la alternancia de código. Revista de la Asociación Europea de Profesores de Español. El español por el mundo, 1, 113-122.

Hinkel, E. (1999). Culture in Second Language Teaching and Learning. Nueva York: Cambridge University Press.

Huber, J.y Reynolds, C. (2014). Developing intercultural competence through education. Strasbourg: Council of Europe Publishing.

Jackson, J. (2014). Introducing Language and Intercultural Communication. New York: Routledge.

Jiménez-Ramírez, J. (2019). Cultura e Interculturalidad. En J. Muñoz-Basols, E. Gironzetti y M. Lacorte (Eds.), The Routledge Handbook of Spanish Language. Metodologias, contextos y recursos para la enseñanza del español L2 (pp. 243-257). Nueva York: Routledge.

Klee, C. (2019). Aprendizaje por contenidos e inmersión lingüística. En J. Muñoz-Basols, E. Gironzetti y M. Lacorte (Eds.), The Routledge Handbook of Spanish Language. Metodologias, contextos y recursos para la enseñanza del español L2 (pp. 491-504). Nueva York: Routledge.

Klee, C. y Barnes-Karol, G. (2006). A Content-Based Approach to Spanish Language Study: Languages across the Curriculum. En R. Salaberry y B. Lafford (Eds.), The Art of Teaching Spanish (pp. 23-38). Washington, DC: Georgetown University Press.

Langacker R. (2009). A Dynamic View of Usage and Language Acquisition. Cognitive Linguistics, 20(3), 627-640.

Lantolf, J. (2000). Sociocultural Theory and Second Language Learning. Oxford: Oxford University Press.

Lantolf, J. y Thorne, S. (2007). Sociocultural Theory and Second Language Learning. En B. VanPatten y J. Williams (Eds.), Theories in Second Language Acquisition (pp. 201-224). Nueva Jersey, EE. UU.: Lawrence Erlbaum.

Liddicoat, A. J. (2009). Communication as Culturally Contexted Practice: A View from Intercultural Communication. Australian Journal of Linguistics, 29(1), 115-133.

Llovet, X. (2007). El caso de la perspectiva del docente en un Enfoque Integrado de Contenidos y Lenguas Extranjeras (EICLE). Biblioteca RedELE, 7.

López, C. y Martín Peris, E. (2011). La competencia crítica en el aula de español L2/LE: textos y contextos. En J. de Santiago Guervós, H. Bongaerts, J. J. Sánchez Iglesias y M. Seseña Gómez (Eds), Actas del XXI Congreso de la ASELE (pp. 507-516). Salamanca: Sadmo.

López, L. (2009). Reaching the Unreached: Indigenous Bilingual Education in Latin America. Recuperado de https:// www.gcedclearinghouse.org/sites/default/files/resources/170088eng.pdf.

Lyster, R. (2007). Learning and Teaching Languages Through Content: A Counterbalanced Approach. Ámsterdam: John Benjamins.

Maljers, A., Marsh, D., Wolff, D., Genesse, F., Frigols-Martin, M. y Mehisto, P. (2010). Diverse Contexts-Converging Goals: CLIL in Europe. Frankfurt: Peter Lang.

Martín Peris, E. (Dir). (2008). Diccionario de términos clave de ELE. Recuperado de https://cvc.cervantes.es/ensenan za/biblioteca_ele/diccio_ele/diccionario/compintercult.htm

McDougald, J. (2009). The State of Language and Content Instruction in Colombia. Latin American Journal of Content and Language Integrated Learning, 2(2), 44-48.

McLaren, P. (2000). Multiculturalismo crítico. São Paulo: Cortez.

Met, M. (1999). Content-Based Instruction: Defining Terms, Making Decisions. Washington, DC: National Foreign Language Research Center.

Naessens, H. (2015). Comparación entre dos autores del pensamiento crítico: Jacques Boisvert y Richard Paul-Linda Elder. En Temas de historia y discontinuidad sociocultural en México (pp. 207-225). Recuperado de http://hdl. handle.net/20.500.11799/57993

Nikula, T. y Moore, P. (2016). Exploring translanguaging in CLIL. International Journal of Bilingual Education and Bilingualism, 22, 1-13.

Oliveras, A. (2000). Hacia la competencia intercultural en el aprendizaje de una lengua extranjera. Estudio del choque cultural y los malentendidos. Madrid: Edinumen. 
Gregorio Pérez de Obanos Romero. Algunas consideraciones metodológicas para la enseñanzaAPRENDIZA...

Pastor, S. (2014). Aprendizaje de contenidos a través del Español como Segunda Lengua en la Educación Superior: un puente entre la lengua y el conocimiento. EuroAmerican Journal of Applied Linguistics and Languages EJournALL, 1(1), 15-30.

Paul, R. y Elder, L. (2003). La mini-guia para el pensamiento critico, conceptos y herramientas. Dillon Beach, California: Fundación para el pensamiento crítico.

Pennycook, A. (2004). Critical Applied Linguistics. En E. Davies y C. Elder (Eds.), The Handbook of Applied Linguistics (pp. 784-807). Massachusetts: Blackwell Publishing.

Pereira, S. (2016). Conciencia metacognitiva y estrategias de lectura en un contexto pro-AICLE a nivel universitario. Ikala, 21, 81-97.

Pérez de Obanos, G. y Ulloa, I. (2019). Prácticas discursivas para la enseñanza-aprendizaje del español en el ámbito universitario. En I. Coelho (Eds), Competências no ensino-aprendizagem de linguas:pressupostos, práticas e reflexões (pp. 245-273). Campinas, Brasil: Pontes.

Pino, A. M., Trujillo, F. y González, A. (2019). Translingüismo: revisión de la literatura y aplicación didáctica para la enseñanza de ELE y ELE 2. Foro de profesores de E/LE, 15, 285-296.

Pombo, O. (Junio, 2004). Interdisciplinaridade e integração dos saberes. Conferencia llevada a cabo en el Congresso Luso-Brasileiro sobre Epistemologia e Interdisciplinaridade na Pos-Graduação. Universidad Pontificia de Rio Grande do Sul, Porto Alegre, Brasil.

Quilaqueo, D. y Torres, H. (2013). Multiculturalidad e Interculturalidad: desafíos epistemológicos de la escolarización desarrollada en contextos indígenas. Alpha, 37, 285-300.

Regueiro, M. L. y Sáez, D. (2013). El español académico. Guía práctica para la elaboración de textos académicos. Madrid: Arco.

República Federativa de Brasil. (2010). Lei de Criação da UNILA - Lei 12189/10. Recuperado de https://presrepubl ica.jusbrasil.com.br/legislacao/821107/lei-de-criacao-da-unila-lei-12189-10

Roberts, C. y Byram, M. (2001). Language Learners as Ethnographers. Clevedon: Multilingual Matters.

Rodrigues, J. y de Faria, M. (2019). Interculturalidade, competência intercultural crítica e ensino-aprendizagem de inglês: contribuições teóricas e práticas a partir de narrativas de duas professoras. En I. Coelho (Eds), Competências no ensino-aprendizagem de línguas:pressupostos, práticas e reflexôes (pp.121-140). Campinas, Brasil: Pontes.

Ruiz de Zarobe, Y. y Lasagabaster, D. (2010). The Emergence of CLIL in Spain: An Educational Challenge. [Introducción]. En D. Lasagabaster y Y. Ruiz de Zarobe (Eds.), CLIL in Spain: Implementation, Results and Teacher Training (p. 1). Newcastle upon Tyne: Cambridge Scholars.

Schlatter, M. y Garcez, P. M. (2009). Educação linguística e aprendizagem de uma língua adicional na escola. En Referências curriculares do Estado do Rio Grande do Sul: linguagens, códigos e suas tecnologias (pp. 127-128). Porto Alegre: Secretaria de Estado da Educação/Departamento Pedagógico.

Stryker, S. y Leaver, B. (1997) Content-based instruction in foreign language education: Models and methods. Washington, DC: Georgetown University Press.

Tedick, D. J. y Cammarata, L. (2012). Balancing Content and Language in Instruction: The experience of immersion Teachers. The Modern Language Journal, 96(2), 251-269.

Ulloa, I. y Pérez de Obanos, G. (2019). Español en la universidad. Prácticas discursivas. Recuperado de https://portal .unila.edu.br/editora/livros/espanol-en-la-universidad

UNILA. (2013a). Regimento Geral da Universidade. Recuperado de https://portal.unila.edu.br/institucional/docum entos-oficiais/pdi-2013-2017

UNILA. (2013b). Projeto Pedagógico - Ciclo Comum de Estudos. Recuperado de https://www.unila.edu.br/sites/defa ult/files/files/PPC2\%20do\%20CICLO\%20COMUM.pdf

UNILA. (2019a). Plano de Desenvolvimento Institucional - PDI - 2019-2023. Recuperado de https://portal.unila.ed u.br/proplan/planejamento/pdi-unila-2019-2023.pdf 
UNILA. (2019b). A internacionalização como ferramenta para o desenvolvimento sustentável. Recuperado de https://portal.unila.edu.br/reitoria/espaco-reitoria/a-internacionalizacao-como-ferramenta-para-o-desenvo lvimento-sustentavel

Van Dijk, T. A. (2008). Discurso e poder. São Paulo: Contexto.

Vázquez, G. (2004). La enseñanza del español con fines académicos. En J. Sánchez Lobato e I. Santos Gargallo (Eds.), Vademécum para la formación de profesores. Enseñar español como segunda lengua y lengua extranjera (pp. 1129-1147). Madrid: SGEL.

Wu, W. (2018). A Vygotskyan Sociocultural Perspective on The Role of L1 in Target Language Learning. Cambridge Open-Review Educational Research e-Journal, 5, 87-103.

\section{Notas}

1 Cuando se mencione la lengua no nativa, se emplea el término lengua adicional por ser más apropiado para el contexto de la UNILA, en el resto de los contextos se empleará el término segunda lengua.

2 En el texto se adopta esta traducción del término translanguaging, frente a otras como translenguar o translingüismo.

3 La universidad se crea en el gobierno de Luis Ignacio Lula da Silva mediante la Ley n 12.189 del 12 de enero de 2010.

4 La UNILA constituye un espacio multilingüe ya que en ella conviven no solamente alumnos cuya L1 es el español o el portugués, sino también lenguas originarias (guaraní, quechua, aimara, entre otras) o el criollo haitiano. Aunque oficialmente la proporción de reserva de plazas para estudiantes es del $50 \%$ para cada grupo, según datos oficiales, en 2019 la proporción era del $79 \%$ de brasileños frente al $21 \%$ del resto de los países (UNILA, $2019 \mathrm{~b}$ ).

5 En lugar de dividirse en departamentos, en la UNILA cada curso de grado está integrado en uno de los denominados Institutos Latinoamericanos. En la actualidad hay cuatro, vinculados a las ciencias humanas, las ciencias exactas, las ciencias sociales y las ciencias de la salud. A su vez, cada Instituto se subdivide en dos Centros Interdisciplinarios que agrupan por afinidad cada una de las carreras y promueven la interdisciplinariedad en su planificación y práctica curricular.

6 Para una revisión histórica y una descripción del panorama actual de estos modelos de enseñanza integrada de lengua y contenido, véase Klee (2019, pp. 492-494).

7 Traducción propia del término theme-based language instruction.

8 Traducción propia del término adjunct instruction.

9 Traducción propia del término sheltered instruction.

10 Desde inicios de 2021, existe una comisión, vinculada al denominado Núcleo Interdisciplinario de Estudios del Lenguaje y la Interculturalidad, que está encargada de elaborar una propuesta de articulación de una Política Lingüística para la universidad.

11 Ver nota a pie de página número seis.

12 Acceso en el Diccionario de términos clave de ELE (Martín Peris, 2008) a la entrada "competencia intercultural" en: https://cvc.cervantes.es/ensenanza/biblioteca_ele/diccio_ele/diccionario/compintercult.htm

13 Traducción del término code-switching. 